\title{
Amino Acids in Prospective Feeds for Fish Aquaculture: a Review of Experimental Data
}

\author{
Vladimir I. Kolmakova,b* and Anzhelika A. Kolmakova ${ }^{\mathrm{a}}$ \\ "Institute of Biophysics $S B$ RAS \\ FRC "Krasnoyarsk Science Center SB RAS" \\ Krasnoyarsk, Russian Federation \\ ${ }^{b}$ Siberian Federal University \\ Krasnoyarsk, Russian Federation
}

Received 12.05.2020, received in revised form 15.09.2020, accepted 28.09.2020, published online 26.11.2020

\begin{abstract}
Total dependence of aquaculture on imports of feeds can significantly compromise Russia's food supply security; hence the task of designing new domestic feeds is of primary importance. A major challenge of world aquaculture is providing fish with a balanced diet, in particular, with a wellbalanced composition of amino acids. In this review, we analyze international publications on the composition of amino acids in fish feed over the last two years. We summarize the data on the amino acid composition of prospective food sources for fish aquaculture: agricultural crops, insects, annelids, higher crustaceans, animal waste, phytoplankton, zooplankton, macrophytes, and microorganisms. We performed a comparative analysis of the composition of amino acids in promising aquafeed sources and fish flour traditionally used for fish feeding. Based on the results, we conclude that each of the examined food sources can be used as a component of fish nutrition and offers realistic prospects for production of alternative feeds. To ensure high quality of fish aquaculture products, the priority should be given to development of technologies which allow to control amino acid feed composition during the production process with respect to fish species-specific needs. It is hoped that this review will be useful to researchers and practitioners involved in designing and producing new domestic aquafeed for fish.
\end{abstract}

Keywords: amino acids, fish feed, fishmeal, diet, aquaculture.

Citation: Kolmakov V.I., Kolmakova A.A. Amino acids in prospective feeds for fish aquaculture: a review of experimental data. J. Sib. Fed. Univ. Biol., 2020, 13(4), 424-442. DOI: 10.17516/1997-1389-0332

(C) Siberian Federal University. All rights reserved

This work is licensed under a Creative Commons Attribution-NonCommercial 4.0 International License (CC BY-NC 4.0).

* Corresponding author E-mail address: vkolmakov@sfu-kras.ru 


\title{
Аминокислоты в перспективных кормах \\ для аквакультуры рыб: \\ обзор экспериментальных данных
}

\author{
В.И. Колмаков ${ }^{\mathrm{a}, \tilde{0}}$, А.А. Колмакова ${ }^{\mathrm{a}}$ \\ ${ }^{a}$ Институт биофизики \\ ФИЦ «Красноярский научный центр СО РАН» \\ Российская Федераџия, Красноярск \\ ${ }^{6}$ Сибирский федеральный университет \\ Российская Федерация, Красноярск
}

\begin{abstract}
Аннотация. Тотальная зависимость от импорта кормов для аквакультуры может стать причиной потери продовольственной безопасности России, поэтому первоочередной задачей является разработка отечественных кормов. Одна из главных проблем мировой аквакультуры-обеспечение рыб рациональным питанием, имеющим сбалансированный состав аминокислот. В настоящем обзоре проведен анализ литературы по составу аминокислот в кормах для рыб, опубликованной в международных журналах по аквакультуре за последние два года. Представлены данные о составе аминокислот в перспективных кормовых объектах для искусственного разведения рыб: сельскохозяйственные растения, насекомые, кольчатые черви, высшие раки, отходы животного производства, фитопланктон, зоопланктон, макрофиты, микроорганизмы. Проведен сравнительный анализ состава аминокислот в перспективных кормах и рыбной муке, традиционно применяемой для рационального кормления рыб. Сделан вывод, что каждый из рассмотренных кормовых объектов по составу аминокислот может быть компонентом питания рыб и представляет собой потенциал для производства альтернативных кормов. Однако для создания качественной товарной рыбопродукции дополнительные преимущества на рынке получат корма, составом аминокислот которых можно управлять при их производстве с учетом видоспецифических потребностей рыб. Предполагается, что вся эта информация будет полезна для разработки и производства новых отечественных кормов для рыб.
\end{abstract}

Ключевые слова: аминокислоты, корм для рыб, рыбная мука, рацион питания, аквакультура.

Цитирование: Колмаков, В.И. Аминокислоты в перспективных кормах для аквакультуры рыб: обзор экспериментальных данных / В.И. Колмаков, А.А. Колмакова // Журн. Сиб. федер. ун-та. Биология, 2020. 13(4). С. 424-442. DOI: 10.17516/1997$1389-0332$

\section{Введение}

Общеизвестно, что рыба является важным и необходимым для здоровья человека продуктом питания, имеющим сбалансированный состав аминокислот (АК). По данным Продовольственной и сельскохозяйственной организации ООН (FAO, 2018), на долю рыбы приходится 17 \% общемирового потребления животного белка населением планеты. Очевидно, что продолжающийся рост населения и повышение благосостояния людей в некоторых крупных азиатских странах (Китай, 
Индия, Индонезия) приводят к формированию устойчивого спроса на рыбу, особенно ценных видов. При этом основные надежды на решение проблемы снабжения человека полноценной рыбной пищей связаны с увеличением продукции аквакультуры (Kwasek et al., 2020). Сейчас ее мировое производство примерно сравнялось с продукцией рыб, выловленных во внутренних водоемах и морях (FAO, 2018). В дальнейшем доля аквакультуры будет расти, так как промысел рыб уже достиг верхнего предела, превышение которого (т.е. перелов) может привести к катастрофическому истощению важнейшего биологического ресурса.

Обеспечение рыб рациональным питанием, имеющим сбалансированный состав АК, одна из главных проблем мировой аквакультуры (Li, Wu, 2020). Для нашей страны данная проблема особенно актуальна. Тотальная зависимость от импорта кормов не позволяет развиваться современному отечественному рыбоводству и может привести к потере продовольственной, а значит, и национальной безопасности. И это в стране, где в 1970-1980-х гг. товарное выращивание рыб было одной из самых передовых и бурно развивающихся отраслей производства. Поэтому в данном обзоре была поставлена задача: познакомить российских рыбоводов, практиков и производителей кормов с результатами исследований состава аминокислот в перспективных кормовых объектах для искусственного разведения рыб, опубликованных в иностранных журналах по аквакультуре за последние два года. Предполагается, что изложенная информация будет востребована практическими специалистами при создании современных отечественных кормов.

В теории “идеальный” рацион по составу АК должен быть аналогичен (или близок) той пище, которую потребляют рыбы в естествен- ных условиях. Однако на практике реализовать это сложно, поэтому длительное время в качестве основного кормового компонента используется рыбная мука (РМ), получаемая после сушки и измельчения рыб или отходов рыбного производства. Было принято, что состав АК в корме должен соответствовать составу АК тела рыб, этим кормом питающихся (Mambrini, Kaushik, 1995). Под составом АК традиционно понимают “процентный состав”, где содержание каждой АК приводится в процентах от суммарного содержания АК.

Как правило, РМ производится путем переработки мелких промысловых пелагических рыб и доля такой “кормовой” рыбы уже превышает $10 \%$ от общего мирового вылова. Так как РМ в большом количестве используется в аквакультуре, а также для кормления сельскохозяйственных (куры, свиньи) и домашних животных (кошки, собаки), то цены на нее постоянно растут (Hodar et al., 2020). Очевидно, что дальнейший рост товарного производства рыбы возможен только за счет замещения РМ альтернативными кормовыми компонентами. В первую очередь к таковым следует отнести сельскохозяйственные растения, насекомых, кольчатых червей, высших раков, отходы животного производства (внутренности, перья, кровь и т.д.), фитопланктон, зоопланктон, высшую водную растительность, гетеротрофные и автотрофные микроорганизмы (Hua et al., 2019). Цель обзора - провести сравнительный анализ состава аминокислот в перспективных кормовых объектах для товарного выращивания рыб и рыбной муке.

\section{Аминокислоты в питании рыб}

Аминокислоты в онтогенезе рыб являются основными субстратами для синтеза белков и биологически активных веществ, а на ранних стадиях развития рыб - основными 
источниками энергии. Потребность в белке у морских рыб составляет $40-55 \%$ от сухой массы кормов, у большинства пресноводных рыб - 28-40 \% (Henry et al., 2015). Однако количество белка в корме важное, но недостаточное условие эффективного питания. В аквакультуре принята концепция “идеального” кормового белка, согласно которой идеальным считается белок со сбалансированным составом АК, наиболее полно соответствующим потребностям питающегося организма. При этом рекомендуется особо учитывать потребности в составе незаменимых АК, т.е. не синтезируемых рыбами. К незаменимым АК
У рыб относятся аргинин, гистидин, изолейцин, лейцин, лизин, метионин, фенилаланин, треонин, триптофан и валин. Исследователи выделяют цистеин и тирозин как условно незаменимые, которые могут быть синтезированы соответственно из метионина и фенилаланина. К условно незаменимым АК у рыб относится и серосодержащий таурин, не входящий в белок и образующийся из цистеина. Полный перечень протеиногенных АК (+ таурин) представлен в таблице.

Незаменимая и условно незаменимая АК, которая присутствует в рационе в наименьшем количестве относительно потреб-

Таблица. Состав аминокислот (среднее $\pm \mathrm{SD}, \%$ от суммы) рыбной муки и перспективных кормов рыб Table. Amino acid composition (mean \pm SD, \% of total) of fish meal and promising fish feed

\begin{tabular}{l|c|c|c|c}
\hline & $\begin{array}{c}\text { Рыбная мука* } \\
(\mathrm{n}=10)\end{array}$ & $\begin{array}{c}\text { Соевая мука** } \\
(\mathrm{n}=6)\end{array}$ & $\begin{array}{c}\text { Личинки мучного } \\
\text { хрущака*** } \\
(\mathrm{n}=6)\end{array}$ & $\begin{array}{c}\text { Личинки } \\
\text { черной львинки**** } \\
(\mathrm{n}=6)\end{array}$ \\
\hline Аргинин & $6,52 \pm 0,62$ & $7,47 \pm 0,27$ & $5,20 \pm 1,45$ & $6,32 \pm 1,94$ \\
Гистидин & $3,17 \pm 0,98$ & $2,88 \pm 0,50$ & $3,93 \pm 0,90$ & $3,21 \pm 0,46$ \\
Изолейцин & $4,28 \pm 0,42$ & $4,66 \pm 0,34$ & $4,97 \pm 0,38$ & $4,88 \pm 1,07$ \\
Лейцин & $8,16 \pm 1,21$ & $7,88 \pm 0,28$ & $8,63 \pm 1,93$ & $7,26 \pm 1,32$ \\
Лизин & $7,75 \pm 1,27$ & $6,70 \pm 0,15$ & $5,81 \pm 0,94$ & $5,99 \pm 1,26$ \\
Метионин & $3,31 \pm 1,15$ & $1,29 \pm 0,17$ & $1,51 \pm 0,48$ & $2,36 \pm 0,87$ \\
Фенилаланин & $4,44 \pm 0,50$ & $5,21 \pm 0,19$ & $3,96 \pm 0,58$ & $4,59 \pm 0,55$ \\
Треонин & $4,51 \pm 0,49$ & $4,12 \pm 0,22$ & $4,02 \pm 0,41$ & $4,37 \pm 0,81$ \\
Триптофан & $0,91 \pm 0,10$ & $1,29 \pm 0,16$ & $1,06 \pm 1,06$ & $1,04 \pm 0,56$ \\
Валин & $5,06 \pm 0,60$ & $4,83 \pm 0,48$ & $6,54 \pm 0,94$ & $6,60 \pm 0,89$ \\
Таурин & $0,54 \pm 0,47$ & $0,32 \pm 0,14$ & н.д. & н.д. \\
Аланин & $6,68 \pm 0,87$ & $4,50 \pm 0,14$ & $8,75 \pm 2,10$ & $7,69 \pm 1,18$ \\
Аспарагин & $9,81 \pm 1,39$ & $11,80 \pm 0,38$ & $8,54 \pm 0,31$ & $9,77 \pm 0,80$ \\
Цистеин & $1,39 \pm 1,13$ & $1,13 \pm 0,52$ & $1,25 \pm 0,91$ & $0,99 \pm 1,33$ \\
Глутаминовая к-та & $15,55 \pm 2,64$ & $19,96 \pm 1,46$ & $12,46 \pm 0,68$ & $12,82 \pm 3,53$ \\
Глицин & $6,17 \pm 1,58$ & $4,45 \pm 0,11$ & $6,49 \pm 2,06$ & $5,96 \pm 0,95$ \\
Пролин & $5,35 \pm 1,38$ & $4,91 \pm 0,57$ & $6,93 \pm 0,55$ & $6,95 \pm 1,83$ \\
Серин & $4,78 \pm 0,96$ & $5,24 \pm 0,38$ & $4,50 \pm 0,53$ & $4,66 \pm 1,24$ \\
Тирозин & $3,42 \pm 0,50$ & $3,36 \pm 0,48$ & $6,52 \pm 1,39$ & $6,23 \pm 1,23$ \\
\hline
\end{tabular}

Источники: * (Bauer et al., 2012; Barnes et al., 2013; Ma et al., 2014; Ding et al., 2015; Riche, 2015; Xie et al., 2016; Belghit et al., 2019; Terova et al., 2019; Hoffmann et al., 2020; Psofakis et al., 2020); ** (Yamamoto et al., 2010; Ma et al., 2014; Ding et al., 2015; Xie et al., 2016; Fisher et al., 2020; Kumar et al., 2020); *** (De Marco et al., 2015; Vrabec et al., 2015; Iaconisi et al., 2019; Nekrasov et al., 2019; Basto et al., 2020; Hoffmann et al., 2020); **** (De Marco et al., 2015; Vrabec et al., 2015; Basto et al., 2020; Renna et al., 2017; Onsongo et al., 2018; Fisher et al., 2020). 
ностей рыб, считается “лимитирующей” рост и развитие. Недостаток АК в рационе может нарушать в организме рыб обмен веществ, гомеостаз, воспроизведение, поведение, снижать иммунитет и устойчивость к болезням. Поэтому для выращивания рыб в аквакультуре необходимо знать их видоспецифичные потребности в АК (Kasozi et al., 2019; Nascimento et al., 2020). При разработке кормов важно учитывать доступность АК для усвоения, а также вкусовые предпочтения и стадию развития рыб (Pfeuti et al., 2019; Feng et al., 2020).

Однако Хоу, Ву и Ли (Hou, Wu, 2017; $\mathrm{Li}, \mathrm{Wu}, 2018)$ критикуют традиционное разделение АК на незаменимые и заменимые в питании животных, в том числе и в аквакультуре. По их мнению, во-первых, функции заменимых АК в организме животного не менее важны, чем незаменимых. Во-вторых, сбалансированное содержание заменимых аминокислот в питании снижает затраты незаменимых АК на синтез de novo заменимых АК в клетках. То есть животным энергетически более выгодно получать заменимые АК с пищей, чем запускать их собственный синтез. Поэтому предлагается изменить диетические требования к заменимым АК и пересмотреть концепцию “идеального” белка (Hou, Wu, 2017).

Информация о роли отдельных АК в питании рыб постоянно дополняется (Liu et al., 2019). Например, недавно доказано инсулинотропное воздействие аргинина у рыб сразу после приема пищи (Hoseini et al., 2020). Также установлено, что потребность в таурине значительно возрастает при недостатке в пище метионина (Candebat et al., 2020). Heсомненно, новые знания о роли АК в питании рыб должны быть использованы при поиске перспективных кормов и составлении рационов.

\section{Сельскохозяйственные растения}

В настоящее время корма растительного происхождения (КРП) из урожая или отходов зерновых, бобовых или масличных растений являются наиболее распространенными среди альтернативных в аквакультуре рыб. В качестве замены традиционной РМ предлагается применять муку из сои, хлопка, пшеницы, гороха, картофеля, конопли, подсолнечника, кунжута и др. (Takakuwa et al., 2020; Mo et al., 2020; Mohammadi et al., 2020; Saleh, 2020). Из всех КРП наиболее соответствующей потребностям большинства видов рыб по составу АК принято считать соевую муку (CM). Поиск эффективных рационов на основе СМ был предпринят для ценных видов из отряда Salmoniformes: радужной форели Oncorhynchus mykiss Walbaum, 1792, атлантического лосося Salmo salar Linnaeus, 1758, северной мальмы Salvelinus malma Walbaum, 1792 (Choi et al., 2020; Krogdahe et al., 2020; Meng et al., 2020). Как правило, для лососеобразных авторы рекомендуют не полную, а частичную замену РМ на СМ.

В таблице, составленной по литературным данным, представлен АК-состав рыбной муки и перспективных кормов. Из этих данных следует, что состав АК СМ близок РМ. Однако у СМ, по сравнению с РМ, содержится достоверно $(\mathrm{p} \leq 0,01)$ больше аргинина, фенилаланина и аспарагиновой кислоты, но меньше аланина и метионина. Заключение о недостаточном содержании в СМ некоторых АК сделано и в других работах (Zhou et al., 2020). Более того, эксперименты по кормлению СМ радужной форели показали, что в организме рыб снижалось содержание изолейцина, лейцина и валина, хотя в рационе этих АК было достаточно (Kumar et al., 2020).

В целом, согласно данным Ли и Ву $(\mathrm{Li}$, $\mathrm{Wu}, 2020)$, КРП отличаются от РМ пониженным содержанием глицина, пролина, глута- 
миновой кислоты, лейцина, лизина и аргинина. Считается, что наиболее чувствителен для рыб в КРП недостаток лизина, который резко снижает показатели роста и размножения (Lee et al., 2020). Как правило, у КРП с дефицитом лизина содержится избыток метионина. И наоборот, при дефиците метионина - избыток лизина. Это позволяет создавать комбинацию растительных компонентов для обеспечения сбалансированного состава метионина и лизина в кормах для рыб. Поэтому получение информации о содержании лизина и метионина в КРП и потребности в этих АК для культивируемых видов рыб являются критически важным условием при разработке эффективных кормов.

Следует указать на существенные ограничения для применения КРП. Во-первых, некоторые КРП могут содержать высокоактивные химические соединения - ингибиторы активности ферментов или различные классы токсинов (Pietsch, 2020). Так, в хлопковой муке присутствует госсипол, блокирующий активность ряда ферментов и препятствующий нормальному синтезу АК у рыб (Wang et al., 2019b). Во-вторых, на состав АК отходов из масличных, бобовых и зерновых культур может негативно влиять способ их промышленной переработки. В-третьих, выращивание сельскохозяйственных растений в будущем потребует расширения пахотных площадей, недостаток которых уже сейчас стал мировой проблемой. В-четвертых, цена и спрос на многие растения (пшеница, кукуруза, хлопок, горох и др.) в качестве продукта питания человека постоянно растет и их применение для корма рыб может стать экономически невыгодным.

Общепризнано, что растительный корм обладает более низким качеством по соотношению протеиногенных АК и худшей усвояемостью, чем корм животного происхож- дения (Hou et al., 2019). Поэтому внимание исследователей все чаще обращается на корм животного происхождения, в первую очередь на беспозвоночных животных, как часть естественного рациона многих видов рыб.

\section{Насекомые}

Из-за высокого содержания белка и сбалансированного состава АК насекомых считают одним из самых перспективных компонентов корма для рыб (Nogales-Merida et al., 2019; Basto et al., 2020). Известно, что состав АК насекомых может изменяться в зависимости от стадии развития: личинка, куколка, нимфа или имаго (Tang et al., 2019). Для аквакультуры особый интерес представляют питающиеся стадии насекомых, чаще всего личинки, обладающие благоприятным для развития рыб составом АК и имеющие быстрый рост для разведения в промышленных масштабах. Из отряда Diptera это такие распространенные виды, как черная львинка Hermetia illucens Linnaeus, 1758, ильница обыкновенная Eristalis tenax Linnaeus, 1758, комнатная муха Musca domestica Linnaeus, 1758, комарзвонец Chironomus sp. (Cappellozza et al., 2019; Guerreiro et al., 2020). Из отряда Coleoptera личинки мучного хрущака Tenebrio molitor Linnaeus, 1758 и чернотелки Zophobas morio Fabricius, 1776 (Nogales-Merida et al., 2019; Hoffmann et al., 2020).

Среди отдельных видов наиболее близкий к РМ состав АК имеют личинки черной львинки и мучного хрущака (таблица). Различие заключается только в повышенном содержании у насекомых валина и тирозина $(\mathrm{p} \leq 0,01)$. Это согласуется с данными исследований, в которых на примере атлантического лосося была показана возможность замены РМ на личинок черной львинки (Belghit et al., 2019; Fisher et al., 2020; Li et al., 2020). Не было обнаружено негативного влияния 
на показатели роста и развития обыкновенного лаврака Dicentrarchus labrax Linnaeus, 1758 при частичной замене в питании РМ на личинок черной львинки (Abdel-Tawwab et al., 2020). Кроме того, установлено, что при кормлении личинками черной львинки радужной форели происходит обогащение кишечника рыб полезными бактериями (Terova et al., 2019). В статье Иакониси с соавторами (Iaconisi et al., 2019) показано, что по составу АК личинки мучного хрущака соответствовали пищевым потребностям золотистого спара Sparus aurata Linnaeus, 1758 и радужной форели.

Перспективный для аквакультуры рыб состав АК имеют куколки одомашненных шелковичных червей Bombyx mori Linnaeus, 1758 из отряда Lepidoptera (Karthick et al., 2019). Они выделяются высокой питательной ценностью (от 52 до 72 \% сырого белка) и повышенным по сравнению с РМ содержанием незаменимых АК: валина, фенилаланина и серосодержащих метионина и цистеина (Hodar et al., 2020). Личинки другого представителя отряда Lepidoptera Imbrasia belina (Westwood, 1849) также имеют близкий к РМ состав АК с повышенным содержанием валина, треонина, триптофана, феналаланина и серосодержащих аминокислот (Моуо et al., 2019). Отдельные авторы (Jozefiak et al., 2019) считают возможным по составу АК использовать в питании рыб представителя отряда Blattoidea таракана Blatta lateralis Walker, 1868. В частности, он рекомендован для замещения РМ в питании радужной форели. Не исключается использование для питания рыб имаго и нимф отряда прямокрылых (Orthoptera): кузнечики, саранча, сверчки (Tang et al., 2019). Однако прямокрылые имеют недостаточное для рыб содержание лизина и метионина, что сближает их с КРП. Препятствием для широкого применения прямокрылых в качестве корма является слабое развитие способов их сбора и технологий выращивания в промышленных масштабах.

В целом, состав АК голометаболических насекомых (подвергаются полной метаморфозе в своем развитии, например Lepidortera) отличается от такового гемиметаболических насекомых (подвергаются неполной метаморфозе, например, Ephemeroptera) содержанием треонина, фенилаланина, пролина и тирозина. Вероятно, это отличие может быть объяснено морфологическими и физиологическими изменениями у насекомых, происходящими при окукливании или развитии нимфы (Dwyer et al., 2018). Можно предположить, что голометаболические насекомые по составу АК лучше соответствуют пищевым потребностям рыб, чем гемиметаболические.

Составом АК личинок насекомых можно управлять посредством варьирования их пищи и условий выращивания. В экспериментах было показано, что при кормлении личинок черной львинки пищей, обогащенной бурой водорослью Ascophyllum nodosum Le Jolis, 1863, в теле насекомых изменялось содержание незаменимых (лизин, метионин, фенилаланин), условно заменимых (тирозин) и заменимых (аспарагиновая кислота, глутаминовая кислота) AK (Liland et al., 2017). Ocoбый интерес вызывает разведение питающихся стадий насекомых на побочных продуктах промышленного или сельскохозяйственного производства или даже на пищевых отходах человека. Недавно в Китае запущены в эксплуатацию заводы по переработке городских пищевых отходов колониями черной львинки (г. Сиань) и тараканов (г. Цзинань). Перерабатывая отходы от нескольких миллионов человек, насекомые сами воспроизводятся в больших масштабах и становятся кормовыми объектами, способными полностью обеспечить потребности аквакультуры. 
Кольчатые черви и высшие раки

Земляные (дождевые), навозные черви и трубочники, относящиеся к классу малощетинковых червей (Oligochaeta), а также полихеты (класс Polychaeta) применяются в кормлении рыб и имеют близкий к РМ coстав AK (Bhuvaneshwaran et al., 2019; Hasan et al., 2019; Krishna, Prabhavathi, 2019; Musyoka et al., 2020; Pombo et al., 2020). В экспериментах по кормлению мальков каспийской воблы Rutilus caspicus Yakovlev, 1870 экстрактом из навозных червей Eisenia foetida Savigny, 1826 была показана достаточность состава АК в пище для нормального роста и развития рыб (Rufchaei et al., 2019). Исследование состава АК полихет Hediste diversicolor OF Müller, 1776 показало, что они имели относительно высокое содержание глицина, пролина, аланина и глутаминовой кислоты (Wang et al., 2019a). Суммарно на эти четыре АК приходилось около 38 \% от общего состава АК, при этом они эффективно функционировали в качестве кормовых аттрактантов и повышали обонятельную чувствительность у рыб. Культивирование водных полихет и олигохет возможно на отходах аквакультурных ферм, что способствует более эффективному использованию ограниченных кормовых ресурсов и приближает состав АК кольчатых червей к потребностям рыб.

Среди представителей отряда высших раков (Decapoda) в пищу рыбам наиболее часто используют креветок, речных раков, бокоплавов в живом или сушеном виде (Salas-Leiton et al., 2020). Несмотря на подходящий для рыб состав АК, чаще всего они только частично (от 10 до 20 \%) заменяют PM (Harlioglu, Farhadi, 2018). Это связано с относительно высокой ценой на выращенную или промысловую продукцию высших раков. Иногда содержание отдельных незаменимых АК у высших раков не соответ- ствует потребностям рыб. Анализ состава АК пресноводного рака Aegla uruguayana Schmitt, 1942 показал недостаток метионина, лизина и аргинина (Musin et al., 2020). Наряду с насекомыми конкурентное преимущество кормов из кольчатых червей и высших раков - это возможность их выращивания с заданным составом АК в зависимости от видоспецифичных потребностей рыб.

\section{Корм из отходов}

\section{животного производства}

Для кормления рыб применяются разнообразные переработанные отходы животного производства, в том числе аквакультуры (Bae et al., 2019; Palupi et al., 2020). Как правило, это мясокостная мука (МКМ) из побочных продуктов переработки птицы и сельскохозяйственных животных: костей, внутренностей, головы, перьев, крови и т.д. Очевидно, что МКМ по составу АК имеет высокое соответствие РМ. Однако некоторые авторы (Dawood et al., 2020a) экспериментально показали, что содержание лизина и метионина в МКМ недостаточно для рыб. С другой стороны, в литературе имеется информация о повышенном содержании в МКМ глицина, пролина, лейцина, аргинина и таурина (Li, $\mathrm{Wu}, 2020)$ - жизненно необходимых AK, которые выполняют многие важные функции у рыб, в том числе участвуют в регуляции экспрессии генов, клеточной сигнализации и антиоксидантных реакций. Очень ценной по составу АК считается кровяная мука, получаемая как побочный продукт на скотобойнях. Она имеет повышенное содержание лизина и гистидина (Hodar et al., 2020). В целом, МКМ - это экономически и экологически выгодный источник АК, поэтому ее следует рассматривать как рентабельный альтернативный ингредиент при составлении кормов для рыб. 


\section{Фитопланктон и зоопланктон}

Для создания сбалансированного состава АК в рационе при искусственном выращивании планктоядных и всеядных рыб, особенно их молоди, рекомендуется в качестве основного или дополнительного ингредиента применять фито- и (или) зоопланктонные организмы в сухом или живом виде (Sarker et al., 2020). В первую очередь, это массовые виды фитопланктона (Chlorella sp., Spirulina sp., Dunaliella sp.) и зоопланктона (Rotifera, Cladocera и Copepoda), для которых разработаны технологии культивирования в промышленных масштабах или массового отлова из искусственных или естественных водоемов (Radhakrishnan et al., 2020; Raji et al., 2020). Состав АК некоторых массовых видов пресноводного планктона представлен в обзорной работе (Kolmakova, Kolmakov, 2019). В пределах вида состав АК зоопланктона зависит от стадии развития, размножения, среды обитания, пищи и сезона (Thera et al., 2020). Считается, что растительноядный зоопланктон имеет, как правило, больше пролина, серина и треонина, чем хищный.

По составу АК эффективным кормом для рыб является промысловый морской криль (сообщество мелких планктонных рачков). Из-за высокой рыночной цены криль не может рассматриваться как заменитель РМ, но рекомендуется как добавка в корм для повышения у рыб эффективности роста, усвояемости рациона, устойчивости к болезням (Tharaka et al., 2020). В литературе особое внимание как к кормовому объекту личинок рыб отводится рачкам артемиям: Artemia salina Linnaeus, 1758 и Artemia franciscana Kellog, 1906 (ElGamal et al., 2020; Radhakrishnan et al., 2020). Благодаря высокому содержанию белка и сбалансированному составу АК цисты и науплии артемий являются одним из лучших кормов для личинок рыб и производятся в мире в промышленных масштабах (Van Stappen et al., 2020). Важно, что составом АК артемий, как и другого культивируемого растительноядного зоопланктона, можно управлять путем изменения их микроводорослевого питания (Balachandar, Rajaram, 2019).

В литературе последних двух лет приведено много экспериментальных данных по искусственному кормлению рыб фитопланктоном. Даже такие виды рыб, как атлантический лосось и молодь желтого окуня Perca flavescens Mitchill, 1814, нормально развивались, когда основным компонентом их пищи были зеленые микроводоросли Scenedesmus sp. и Haematococcus pluvialis Flotow, 1844 coответственно (Gong et al., 2019; Jiang et al., 2019). Можно сделать предположение, что в будущем фитопланктон будет широко применяться как компонент для балансировки состава АК в кормах для рыб.

\section{Макрофиты}

В настоящее время пресноводная растительность все чаще применяется как кормовой объект аквакультуры рыб. Например, ряска Spirodela polyrhiza L. Schleiden, водяной латук Pistia stratiotes L., водный папоротник Salvania molesta D.S. Mitch. (Goswami et al., 2020). Очень перспективной считается ряска, преимущество которой заключается, вопервых, в высокой доле лейцина, изолейцина, валина (более 50 \% от всех незаменимых АК), лимитирующих рост и развитие рыб, вовторых, в относительно высокой доле незаменимых АК (около 37 \%) (Sharma et al., 2019). В качестве пищевых добавок в рационах рыб используются морские макроводоросли: красные Rhodophyta (Eucheuma sp., Gracilaria sp., Porphyra sp.), бурые Phaeophyta (Laminaria japonica Aresch., Laminaria saccharina Lamour) и зеленые Chlopohyta (Ulva ohnoi Hiraoka \& Shimada) (Vega et al., 2020). Состав АК макро- 
водорослей видоспецифичен, зависит от вегетационного сезона и условий окружающей среды. Хотя для макроводорослей характерно относительно невысокое содержание белков (от 10 до $30 \%$ в сухой биомассе), но они обладают повышенным содержанием незаменимых АК по сравнению с КРП и РМ (Overland et al., 2019). Следовательно, морская и пресноводная растительность, которую можно выращивать в промышленных масштабах или получать в виде урожая после укоса дикоросов, - перспективный корм для рыб.

\section{Микроорганизмы}

Бактерии и дрожжи имеют относительно высокое содержание белка (от 45 до 65 \%), подходящий для рыб состав АК и большую скорость размножения, что и определило их широкое применение в качестве компонентов корма для рыб (Gamboa-Delgado, MarquezReyes, 2018; Wang et al., 2020; Jones et al., 2020). В экспериментах с молодью белого морского окуня Lates calcarifer Bloch, 1790 была показана возможность частичной замены корма из РМ на искусственно выращенную биомассу фиолетовых фототрофных бактерий, подходящую для рыб по составу АК (DelamareDeboutteville et al., 2019). Также установлено, что дрожжи Saccharomyces cerevisiae Meyen, 1838, Candida utilis Henneberg, 1926 и Kluyveromyces marxianus Hansen, 1888 обладают соответствующим составом АК для их включения в рацион таких ценных видов рыб, как атлантический лосось и радужная форель (Overland, Skrede, 2017). Важно, что состав АК микроорганизмов можно изменять в зависимости от потребности рыб путем изменений условий выращивания и (или) состава питательных сред даже при крупномасштабном производстве. В литературе особо отмечается экономическая и экологическая выгода применения микроорганизмов при производстве кормов для рыб (Hua et al., 2019). Благодаря жизнедеятельности микроорганизмов возможна переработка и преобразование питательных веществ из фекалий, остатков мертвых тел, непищевых продуктов животного происхождения (перья, кожа) в биомассу, которая будет иметь сбалансированный состав АК для питания рыб.

\section{Смешанные корма}

Существует значительный интерес к разработке рационов, основанных на смешанных кормах, которые поддерживают показатели роста рыб на необходимом уровне (Doughty et al., 2019; Nguyen et al., 2020). Личинки черной львинки и мучного хрущака в сравнении с СМ содержат больше валина, аланина, тирозина, но меньше аспарагиновой кислоты ( $<0,01)$ (таблица). Комбинирование в рационе СМ и насекомых позволяет приблизить состав АК к оптимальному для конкретного вида рыб. При составлении рационов часто комбинируют три компонента: РМ, МКМ и КРП. Например, смешанные корма со сбалансированным составом АК были рекомендованы для атлантического лосося и молоди гибридного групера Epinephelus fuscoguttatus + Forsskal, $1775 \times$ Epinephelus lanceolatus ô Bloch, 1790 (Fisher et al., 2020; Zhou et al., 2020). Следует отметить, что все чаще РМ отводится роль не основного, а только дополнительного компонента корма.

Иногда для снятия дефицита некоторых незаменимых АК предлагается добавлять в питание рыб синтетические аминокислоты в виде кристаллов (Martins et al., 2020; Nguyen et al., 2020). Главным образом, это относится к метионину и лизину. Поэтому при выращивании молоди рыб, особенно лососевых и карповых рыб на КРП, рекомендуется обогащать их питание синтетическим лизином и метионином. В качестве обогатителя кормов 
также полезно применять специальные пищевые добавки, способствующие регенерации и повышению доступности АК (Liu et al., 2020; Volatiana et al., 2020). Не исключается использование в кормах компонентов из генетически модифицированных организмов (ГМО) с заданным составом АК, особенно в странах, где нет законодательных запретов для применения ГМО в пищу человека.

В настоящее время в качестве корма рыб применяют микробно-животные или микробно-растительные смеси (компосты) (Dawood et al., 2020b). Показано, что при длительном приеме таких компостов у рыб происходит накопление отдельных АК, особенно в мышцах. Все чаще на аквафермах внедряются замкнутые технологии, способные одновременно очищать сточные воды аквакультуры и производить корм для рыб (Durigon et al., 2020; Silva et al., 2020). Такой корм (biofloc meal) по составу АК соответствует потребностям рыб и представляет собой смесь водных организмов (микроводоросли, нематоды, копеподы и др.), используемых для очистки сточных вод. Считается, что выращенная на смешанных кормах рыба по составу АК более соответствует пищевым потребностям человека, чем выращенная на монокормах.

\section{Заключение}

В настоящее время сбалансированный состав АК (особенно незаменимых) в корме рыб - обязательное условие при выходе коммерческого кормового продукта на рынок. Каждый из рассмотренных кормовых объектов (сельскохозяйственные растения, беспозвоночные, отходы переработки животных, фито- и зоопланктон, высшая водная растительность, микроорганизмы) по составу АК может быть пищей для рыб и представляет собой огромный потенциал для производства альтернативных кормов. Однако для созда- ния качественной товарной рыбопродукции дополнительные конкурентные преимущества на рынке получат корма, имеющие сбалансированный состав АК с учетом видоспецифичных потребностей рыб. Во-первых, это смешанные корма, представляющие собой комплекс растительных, животных и микробных ингредиентов. Во-вторых, монокорма из беспозвоночных или микроорганизмов, состав АК которых можно совершенствовать при их воспроизводстве. Это не исключает продолжение поиска в природе отдельных организмов, которые универсально соответствуют пищевым потребностям конкретного вида рыб.

Полный цикл от научной разработки до промышленного производства новых кормов для рыб должен проводиться с учетом экономической рентабельности аквакультуры и включать применение экологически безопасных технологий. Для этого требуется системный междисциплинарный подход и объединение усилий исследователей и практиков различных областей, таких как биотехнология, биохимия, ихтиология и рыбоводство. По нашему мнению, в будущем РМ не должна быть единственным эталоном для создания новых кормов. Состав АК рациона отдельных видов рыб, выращиваемых в искусственных условиях, следует приближать к составу АК их традиционных кормов в естественных условиях, а не к составу АК тел рыб.

В литературе большое количество статей посвящено изучению состава АК в кормах и его влиянию на улучшение роста и развития рыб. При этом почти нет работ, направленных на исследование влияния модификации состава АК в рыбных кормах на здоровье людей, потребляющих рыбу. Эта тема требует неотложного внимания, так как главная цель аквакультуры рыб - обеспечение качественной пищей человека. 


\section{Благодарности / Acknowledgements}

Работа поддержана Государственным заданием в рамках программы фундаментальных исследований РФ, тема № 51.1.1.

This research was funded by the State Assignment within the framework of the fundamental research program of the Russian Federation, topic No. 51.1.1.

\section{Список литературы / References}

Abdel-Tawwab M., Khalil R.H., Metwally A.A., Shakweer M.S., KhallafM.A., Abdel-LatifH.M.R. (2020) Effects of black soldier fly (Hermetia illucens L.) larvae meal on growth performance, organs-somatic indices, body composition, and hemato-biochemical variables of European sea bass, Dicentrarchus labrax. Aquaculture, 522: 735136

Bae J.B., Azad A.K., Won S., Hamidoghli A., Seong M., Bai S.C. (2019) Effects of enzymatically hydrolyzed fish by-products in diet of juvenile rainbow trout (Oncorhynchus mykiss). Fisheries and Aquatic Sciences, 22: 1

Balachandar S., Rajaram R. (2019) Influence of different diets on the growth, survival, fecundity and proximate composition of brine shrimp Artemia franciscana (Kellog, 1906). Aquaculture Research, 50(2): 376-389

Barnes M.E., Brown M.L., Rosentrater K.A., Sewell J.R. (2013) Preliminary evaluation of rainbow trout diets containing PepSoyGen, a fermented soybean meal product, and additional amino acids. The Open Fish Science Journal, 6: 19-27

Basto A., Matos E., Valente L.M.P. (2020) Nutritional value of different insect larvae meals as protein sources for European sea bass (Dicentrarchus labrax) juveniles. Aquaculture, 521: 735085

Bauer W., Prentice-Hernaudez C., Tesser M.B., Wasielesky W., Poersch L.H.S. (2012) Substitution of fishmeal with microbial floc meal and soy protein concentrate in diets for the pacific white shrimp Litopenaeus vannamei. Aquaculture, 342-343: 112-116

Belghit I., Liland N.S., Gjesdal P., Biancarosa I., Menchetti E., Li Y., Waagbø R., Krogdahl A., Lock E.-J. (2019) Black soldier fly larvae meal can replace fish meal in diets of sea-water phase Atlantic salmon (Salmo salar). Aquaculture, 503: 609-619

Bhuvaneshwaran T., Sanjay G., Jayakumar N., Ahilan B., Felix N., Prabu E. (2019) Potentiality of earthworm as a replacement for fish meal and its role in aquaculture. Journal of Aquaculture in the Tropics, 34: 115-127

Candebat C.L., Booth M., Codabaccus M.B., Pirozzi I. (2020) Dietary methionine spares the requirement for taurine in juvenile Yellowtail Kingfish (Seriola lalandi). Aquaculture, 522: 735090

Cappellozza S., Leonardi M.G., Savoldelli S., Carminati D., Rizzolo A., Cortellino G., Terova G., Moretto E., Badaile A., Concheri G., Saviane A., Bruno D., Bonelli M., Caccia S., Casartelli M., Tettamanti G. (2019) A first attempt to produce proteins from insects by means of a circular economy. Animals, 9(5): 278

Choi D.G., He M., Fang H., Wang X.L., Li X.Q., Leng X.J. (2020) Replacement of fish meal with two fermented soybean meals in diets for rainbow trout (Oncorhynchus mykiss). Aquaculture Nutrition, 26(1): 37-46 
Dawood M.A.O., Magouz F.I., Essa M., Mansour M. (2020a) Impact of yeast fermented poultry by-product meal on growth, digestive enzyme activities, intestinal morphometry and immune response traits of common carp (Cyprinus carpio). Annals of Animal Science, 20(3): 939-959

Dawood M.A.O., Magouz F.I., Mansour M., Saleh A.A., El Asely A.M., Fadl S.E., Ahmed H.A., Al-Ghanim K.A., Mahboob S., Al-Misned F. (2020b) Evaluation of yeast fermented poultry by-product meal in Nile Tilapia (Oreochromis niloticus) feed: Effects on growth performance, digestive enzymes activity, innate immunity, and antioxidant capacity. Frontiers in Veterinary Science, 6: 516

Delamare-Deboutteville J., Batstone D.J., Kawasaki M., Stegman S., Salini M., Tabrett S., Smullen R., Barnes A.C., Hulsen T. (2019) Mixed culture purple phototrophic bacteria is an effective fishmeal replacement in aquaculture. Water Research X, 4: 100031

De Marco M., Martinez S., Hernandez F., Madrid J., Gai F., Rotolo L., Belforti M., Bergero D., Katz H., Dabbou S., Kovitvadhi A., Zoccarato I., Gasco L., Schiavone A. (2015) Nutritional value of two insect larval meals (Tenebrio molitor and Hermetia illucens) for broiler chickens: Apparent nutrient digestibility, apparent ileal amino acid digestibility and apparent metabolizable energy. Animal Feed Science and Technology, 209: 211-218

Ding Z., Zhang Y., Ye J., Du Z., Kong Y. (2015) An evaluation of replacing fish meal with fermented soybean meal in the diet of Macrobrachium nipponense: Growth, nonspecific immunity, and resistance to Aeromonas hydrophila. Fish \& Shellfish Immunology, 44(1): 295-301

Doughty K.H., Garner S.R., Bernards M.A., Heath J.W., Neff B.D. (2019) Effects of dietary fishmeal substitution with corn gluten meal and poultry meal on growth rate and flesh characteristics of Chinook salmon (Oncorhynchus tshawytscha). International Aquatic Research, 11(4): 325-334

Durigon E.G., Lazzari R., Uczay J., Lopes D.L.A., Jeronimo G.T., Sgnaulin T., Emerenciano M.G.C. (2020) Biofloc technology (BFT): Adjusting the levels of digestible protein and digestible energy in diets of Nile tilapia juveniles raised in brackish water. Aquaculture and Fisheries, 5(1): 42-51

Dwyer G.K., Stoffels R.J., Rees G.N., Shackleton M.E., Silvester E. (2018) A predicted change in the amino acid landscapes available to freshwater carnivores. Freshwater Science, 37(1): 108-120

El-Gamal M.M., Othman S.I., Ab-del-Rahim M.M., Mansour A.T., Alsaqufi A.S., El Atafy M.M., Mona M.H., Allam A.A. (2020) Palaemon and artemia supplemented diet enhances sea bass, Dicentrarchus labrax, broodstock reproductive performance and egg quality. Aquaculture Reports, 16: 100290

FAO (Food and Agriculture Organization) (2018) The state of world fisheries and aquaculture: Meeting the sustainable development goals. Rome, $210 \mathrm{p}$.

Feng H., Yi K., Qian X., Niu X., Sun Y., Ye J. (2020) Growth and metabolic responses of juvenile grouper (Epinephelus coioides) to dietary methionine/cystine ratio at constant sulfur amino acid levels. Aquaculture, 518: 734869

Fisher H.J., Collins S.A., Hanson C., Mason B., Colombo S.M., Anderson D.M. (2020) Black soldier fly larvae meal as a protein source in low fish meal diets for Atlantic salmon (Salmo salar). Aquaculture, 521: 734978

Gamboa-Delgado J., Marquez-Reyes J.M. (2018) Potential of microbial-derived nutrients for aquaculture development. Reviews in Aquaculture, 10(1): 224-246

Gong Y., Bandara T., Huntley M., Johnson Z.I., Dias J., Dahle D., Sørensen M., Kiron V. (2019) Microalgae Scenedesmus sp. as a potential ingredient in low fishmeal diets for Atlantic salmon (Salmo salar L.). Aquaculture, 501: 455-464 
Goswami R.K., Shrivastav A.K., Sharma J.G., Tocher D.R., Chakrabarti R. (2020) Growth and digestive enzyme activities of rohu labeo rohita fed diets containing macrophytes and almond oil-cake. Animal Feed Science and Technology, 263: 114456

Guerreiro I., Castro C., Antunes B., Coutinho F., Rangel F., Couto A., Serra C.R., Peres H., PousaoFerreira P., Matos E., Gasco L., Gai F., Corraze G., Oliva-Teles A., Enes P. (2020) Catching black soldier fly for meagre: Growth, whole-body fatty acid profile and metabolic rsponses. Aquaculture, 516: 734613

Harlioglu M.M., Farhadi A. (2018) Importance of Gammarus in aquaculture. Aquaculture International, 26(6): 1327-1338

Hasan M., Haque M.I., Akter N., Rahman M.S., Eti A.S. (2019) Effects of wetting media cattle blood, rice gruel and water on the yield and amino acid composition of tubificid worms. Journal of the Asiatic Society of Bangladesh, Science, 45(2): 229-239

Henry M., Gasco L., Piccolo G., Fountoulaki E. (2015) Review on the use of insects in the diet of farmed fish: past and future. Animal Feed Science and Technology, 203: 1-22

Hodar A.R., Vasava R.J., Mahavadiya D.R., Joshi N.H. (2020) Fish meal and fish oil replacement for aqua feed formulation by using alternative sources: a review. Journal of Experimental Zoology India, 23(1): 13-21

Hoffmann L., Rawski M., Nogales-Merida S., Mazurkiewicz J. (2020) Dietary inclusion of Tenebrio molitor meal in sea trout larvae rearing: effects on fish growth performance, survival, condition, and GIT and liver enzymatic activity. Annals of Animal Science, 20(2): 579-598

Hoseini S.M., Khan M.A., Yousefi M., Costas B. (2020) Roles of arginine in fish nutrition and health: insights for future researches. Reviews in Aquaculture, 12(4): 2091-2108

Hou Y., He W., Hu S., Wu G. (2019) Composition of polyamines and amino acids in plant-source foods for human consumption. Amino Acids, 51(8): 1153-1165

Hou Y., Wu G. (2017) Nutritionally nonessential amino acids: a misnomer in nutritional sciences. Advances in Nutrition, 8(1): 137-139

Hua K., Cobcroft J.M., Cole A., Condon K., Jerry D.R., Mangott A., Praeger Ch., Vucko M.J., Zeng Ch., Zenger K., Strugnell J.M. (2019) The future of aquatic protein: Implications for protein sources in aquaculture diets. One Earth, 1(3): 316-329

Iaconisi V., Secci G., Sabatino G., Piccolo G., Gasco L., Papini A.M., Parisi G. (2019) Effect of mealworm (Tenebrio molitor L.) larvae meal on amino acid composition of gilthead sea bream (Sparus aurata L.) and rainbow trout (Oncorhynchus mykiss W.) fillets. Aquaculture, 513: 734403

Jiang M., Zhao H.H., Zai S.W., Shepherd B., Wen H., Deng D.F. (2019) A defatted microalgae meal (Haematococcus pluvialis) as a partial protein source to replace fishmeal for feeding juvenile yellow perch Perca flavescens. Journal of Applied Phycology, 31(2): 1197-1205

Jones S.W., Karpol A., Friedman S., Maru B.T., Tracy B.P. (2020) Recent advances in single cell protein use as a feed ingredient in aquaculture. Current Opinion in Biotechnology, 61: $189-197$

Jozefiak A., Nogales-Merida S., Mikolajczak Z., Rawski M., Kieronczyk B., Mazurkiewicz J. (2019) The utilization of full-fat insect meal in rainbow (Oncorhynchus mykiss) nutrition: the effects on growth performance, intestinal microbiota and gastrointestinal tract histomorphology. Annals of Animal Science, 19(3): 747-765 
Karthick Raja P., Aanand S., Stephen Sampathkumar J., Padmavathy P. (2019) Silkworm pupae meal as alternative source of protein in fish feed. Journal of Entomology and Zoology Studies, 7(4): 78-85

Kasozi N., Iwe G., Sadik K., Asizua D., Namulawa V.T. (2019) Dietary amino acid requirements of pebbly fish, Alestes baremoze (Joannis, 1835) based on whole body amino acid composition. Aquaculture Reports, 14: 100197

Kolmakova A.A., Kolmakov V.I. (2019) Amino acid composition of green microalgae and diatoms, cyanobacteria, and zooplankton (review). Inland Water Biology, 12(4): 452-461

Krishna P.V., Prabhavathi K. (2019) Efficacy and suitability of earth worm Megascolex sps as supplementary feed for cat fish Pangasius hypophthalmus in response to different animal protein sources. International Journal of Fisheries and Aquatic Studies, 7(1): 160-165

Krogdahl A., Kortner T.M., Jaramillo-Torres A., Gamil A.A.A., Chikwati E., Li Y., Schmidt M., Herman E., Hymowitz T., Teimouri S., Storebakken T. (2020) Removal of three proteinaceous antinutrients from soybean does not mitigate soybean-induced enteritis in Atlantic salmon (Salmo salar, L). Aquaculture, 514: 734495

Kumar V., Lee S., Cleveland B.M., Romano N., Lalgudi R.S., Benito M.R., McGraw B., Hardy R.W. (2020) Comparative evaluation of processed soybean meal (EnzoMeal $\left.{ }^{\mathrm{TM}}\right) v s$. regular soybean meal as a fishmeal replacement in diets of rainbow trout (Oncorhynchus mykiss): Effects on growth performance and growth-related genes. Aquaculture, 516: 734652

Kwasek K., Thorne-Lyman A.L., Phillips M. (2020) Can human nutrition be improved through better fish feeding practices? A review paper. Critical Reviews in Food Science and Nutrition, 60(22): 3822-3835

Lee S., Small B.C., Patro B., Overturf K., Hardy R.W. (2020) The dietary lysine requirement for optimum protein retention differs with rainbow trout (Oncorhynchus mykiss Walbaum) strain. Aquaculture, 514: 734483

Li P., Wu G. (2018) Roles of dietary glycine, proline, and hydroxyproline in collagen synthesis and animal growth. Amino Acids, 50(1): 29-38

Li P., Wu G. (2020) Composition of amino acids and related nitrogenous nutrients in feedstuffs for animal diets. Amino Acids, 52(4): 523-542

Li Y., Kortner T.M., Chikwati E.M., Belghit I., Lock E.-J., Krogdahl A. (2020) Total replacement of fish meal with black soldier fly (Hermetia illucens) larvae meal does not compromise the gut health of Atlantic salmon (Salmo salar). Aquaculture, 520: 734967

Liland N.S., Biancarosa I., Araujo P., Biemans D., Bruckner C.G., Waagbo R., Torstensen B.E., Lock E.-J. (2017) Modulation of nutrient composition of black soldier fly (Hermetia illucens) larvae by feeding seaweed-enriched media. PLOS ONE, 12(8): e 0183188

Liu C., Wang X., Zhou H., Mai K., He G. (2019) Recent advances in amino acid sensing and new challenges for protein nutrition in aquaculture. Marine Life Science \& Technology, 1: 50-59

Liu X.-W., Feng L., Jiang W.-D., Wu P., Jiang J., Yang D.-M., Tang L., Kuang S.-Y., Shi H.-Q., Zhou X.-Q., Liu Y. (2020) (2-Carboxyethyl)dimethylsulfonium Bromide (Br-DMPT) improves muscle flesh quality and antioxidant status of on-growing grass carp (Ctenopharyngodon idella) fed non-fish meal diets. Aquaculture, 521: 735065

Ma X., Wang F., Han H., Wang Y., Lin Y. (2014) Replacement of dietary fish meal with poultry byproduct meal and soybean meal for golden pompano, Trachinotus ovatus, reared in net pens. Journal of the World Aquaculture Society, 45(6): 662-671 
Mambrini M., Kaushik S.J. (1995) Indispensable amino acid requirements of fish: correspondence between quantitative data and amino acid profiles of tissue proteins. Journal of Applied Ichthyology, 11(3-4): 240-247

Martins G.P., Mazini B.S.M., Campos M.A.F., Oliveira D.S., Guimaraes I.G. (2020) Effect of replacing fish meal protein by crystalline amino acid and soy protein concentrate on growth, feed utilization, and metabolism of tambaqui Colossoma macropomum juveniles. Journal of the World Aquaculture Society, 51(5): 1250-1269

Meng F., Li B., Xie Y., Li M., Wang R. (2020) Substituting fishmeal with extruded soybean meal in diets did not affect the growth performance, hepatic enzyme activities, but hypoxia tolerance of Dolly Varden (Salvelinus malma) juveniles. Aquaculture Research, 51(1): 379-388

Mo W.Y., Man Y.B., Wong M.H. (2020) Soybean dreg pre-digested by enzymes can effectively replace part of the fishmeal included in feed pellets for rearing gold-lined seabream. Science of the Total Environment, 704: 135266

Mohammadi M., Imani A., Farhangi M., Gharaei A., Hafezieh M. (2020) Replacement of fishmeal with processed canola meal in diets for juvenile Nile tilapia (Oreochromis niloticus): Growth performance, mucosal innate immunity, hepatic oxidative status, liver and intestine histology. Aquaculture, 518: 734824

Moyo S., Masika P.J., Muchenje V. (2019) The potential of Imbrasia belina worm as a poultry and fish feed. A review. Journal of Animal and Feed Sciences, 28(3): 209-219

Musin G.E., Carvalho D.A., Viozzi M.F., Mora M.C., Collins P.A., Williner V. (2020) Protein and cellulose level in diet: Effects on enzymatic activity, metabolite and amino acid profiles in freshwater anomurans Aegla uruguayana (Decapoda: Anomura). Aquaculture Research, 51(3): 1232-1243

Musyoka S.N., Liti D., Ogello E.O., Meulenbroek P., Waidbacher H. (2020) Earthworm, Eisenia fetida, bedding meal as potential cheap fishmeal replacement for semi-intensive farming of Nile Tilapia, Oreochromis niloticus. Aquaculture Research, 51(6): 2359-2368

Nascimento T.M.T., Mansano C.F.M., Peres H., Rodrigues F.H.F., Khan K.U., Romaneli R.S., Sakomura N.K., Fernandes J.B.K. (2020) Determination of the optimum dietary essential amino acid profile for growing phase of Nile tilapia by deletion method. Aquaculture, 523: 735204

Nekrasov R.V., Chabaev M.G., Zelenchenkova A.A., Bastrakov A.I., Ushakova N.A. (2019) Nutritional properties of Hermetia illucens L., a new feed product for young pigs (Sus scrofa domesticus Erxleben). Sel'skokhozyaistvennaya Biologiya, 54(2): 316-325

Nguyen L., Salem S.M.R., Salze G.P., Dinh H., Davis D.A. (2020) Optimizing amino acid balance in diets for Nile tilapia Oreochromis niloticus. Aquaculture, 515: 734566

Nogales-Merida S., Gobbi P., Jozefiak D., Mazurkiewicz J., Dudek K., Rawski M., Kieronczyk B., Jozefiak A. (2019) Insect meals in fish nutrition. Reviews in Aquaculture, 11(4): 1080-1103

Onsongo V.O., Osuga I.M., Gachuiri C.K., Wachira A.M., Miano D.M., Tanga C.M., Ekesi S., Nakimbugwe D., Fiaboe K.K.M. (2018) Insects for income generation through animal feed: Effect of dietary replacement of soybean and fish meal with black soldier fly meal on broiler growth and economic performance. Journal of Economic Entomology, 111(4): 1966-1973

Overland M., Mydland L.T., Skrede A. (2019) Marine macroalgae as sources of protein and bioactive compounds in feed for monogastric animals. Journal of the Science of Food and Agriculture, 99(1): $13-24$ 
Overland M., Skrede A. (2017) Yeast derived from lignocellulosic biomass as a sustainable feed resource for use in aquaculture. Journal of the Science of Food and Agriculture, 97(3): 733-742

Palupi E.T., Setiawati M., Lumlertdacha S., Suprayudi M.A. (2020) Growth performance, digestibility, and blood biochemical parameters of Nile tilapia (Oreochromis niloticus) reared in floating cages and fed poultry by-product meal. Journal of Applied Aquaculture, 32(1): 16-33

Pfeuti G., Cant J.P., Shoveller A.K., Bureau D.P. (2019) A novel enzymatic pre-treatment improves amino acid utilization in feather meal fed to rainbow trout (Oncorhynchus mykiss). Aquaculture Research, 50(5): 1459-1474

Pietsch C. (2020) Risk assessment for mycotoxin contamination in fish feeds in Europe. Mycotoxin Research, 36(1): 41-62

Pombo A., Baptista T., Granada L., Ferreira S.M.F., Goncalves S.C., Anjos C., Sa E., Chainho P., Fonseca L.C., Costa P.F., Costa J.L. (2020) Insight into aquaculture's potential of marine annelid worms and ecological concerns: a review. Reviews in Aquaculture, 12(1): 107-121

Psofakis P., Karapanagiotidis I.T., Malandrakis E.E., Golomazou E., Exadactylos A., Mente E. (2020) Effect of fishmeal replacement by hydrolyzed feather meal on growth performance, proximate composition, digestive enzyme activity, haematological parameters and growth-related gene expression of gilthead seabream (Sparus aurata). Aquaculture, 521: 735006

Radhakrishnan D.K., AkbarAli I., Schmidt B.V., John E.M., Sivanpillai S., Vasunambesan S.T. (2020) Improvement of nutritional quality of live feed for aquaculture: An overview. Aquaculture Research, 51(1): 1-17

Raji A.A., Jimoh W.A., Abu Bakar N.H., Mohd Taufek N.H., Muin H., Alias Z., Milow P., Abdul Razak S. (2020) Dietary use of Spirulina (Arthrospira) and Chlorella instead of fish meal on growth and digestibility of nutrients, amino acids and fatty acids by African catfish. Journal of Applied Phycology, 32: 1763-1770

Renna M., Schiavone A., Gai F., Dabbou S., Lussiana C., Malfatto V., Prearo M., Capucchio M.T., Biasato I., Biasibetti E., De Marco M., Brugiapaglia A., Zoccarato I., Gasco L. (2017) Evaluation of the suitability of a partially defatted black soldier fly (Hermetia illucens L.) larvae meal as ingredient for rainbow trout (Oncorhynchus mykiss Walbaum) diets. Journal of Animal Science and Biotechnology, 8: 57

Riche M. (2015) Nitrogen utilization from diets with refined and blended poultry by-products as partial fish meal replacements in diets for low-salinity cultured Florida pompano, Trachinotus carolinus. Aquaculture, 435: 458-466

Rufchaei R., Hoseinifar S.H., Nedaei S., Bagheri T., Ashouri G., Van Doan H. (2019) Non-specific immune responses, stress resistance and growth performance of Caspian roach (Rutilus caspicus) fed diet supplemented with earthworm (Eisenia foetida) extract. Aquaculture, 511: 734275

Salas-Leiton E., Hachero-Cruzado I., Asensio E., Vilas C., Zerolo R., Canavate J.P. (2020) Valorisation and enhanced sustainability of Senegalese sole (Solea senegalensis) aquaculture by dietary use of ditch shrimp (Palaemonetes varians) meal. Aquaculture, 522: 735104

Saleh N.E. (2020) Assessment of sesame meal as a soybean meal replacement in European sea bass (Dicentrarchus labrax) diets based on aspects of growth, amino acid profiles, haematology, intestinal and hepatic integrity and macroelement contents. Fish Physiology and Biochemistry, 46(3): 861-879 
Sarker P.K., Kapuscinski A.R., Vandenberg G.W., Proulx E., Sitek A.J. (2020) Towards sustainable and ocean-friendly aquafeeds: Evaluating a fish-free feed for rainbow trout (Oncorhynchus mykiss) using three marine microalgae species. Elementa: Science of the Anthropocene, 8: 5

Sharma J., Clark W.D., Shrivastav A.K., Goswami R.K., Tocher D.R., Chakrabarti R. (2019) Production potential of greater duckweed Spirodela polyrhiza (L. Schleiden) and its biochemical composition evaluation. Aquaculture, 513: 734419

Silva M.A., Alvarenga E.R., Costa F.F.B., Turra E.M., Alves G.F.O., Manduca L.G., Sales S.C.M., Leite N.R., Bezerra V.M., Moraes S.G.S., Teixeira E.A. (2020) Feeding management strategies to optimize the use of suspended feed for Nile tilapia (Oreochromis niloticus) cultivated in bioflocs. Aquaculture Research, 51(2): 605-615

Takakuwa F., Suzuri K., Horikawa T., Nagahashi K., Yamada S., Biswas A., Tanaka H. (2020) Availability of potato protein concentrate as an alternative protein source to fish meal in greater amberjack (Seriola dumerili) diets. Aquaculture Research, 51(3): 1293-1302

Tang C., Yang D., Liao H., Sun H., Liu C., Wei L., Li F. (2019) Edible insects as a food source: a review. Food Production, Processing and Nutrition, $1: 8$

Terova G., Rimoldi S., Ascione C., Gini E., Ceccotti C., Gasco L. (2019) Rainbow trout (Oncorhynchus mykiss) gut microbiota is modulated by insect meal from Hermetia illucens prepupae in the diet. Reviews in Fish Biology and Fisheries, 29(2): 465-486

Tharaka K., Benitez-Santana T., Gunathilaka B.E., Kim M.-G., Lee C., Shin J., Lee K.-J. (2020) Evaluation of Antarctic krill (Euphausia superba) meal supplementation in diets for olive flounder (Paralichthys olivaceus). Aquaculture Research, 51(6): 2291-2302

Thera J.C., Kidd K.A., Bertolo R.F. (2020) Amino acids in freshwater food webs: Assessing their variability among taxa, trophic levels, and systems. Freshwater Biology, 65(6): 1101-1113

Van Stappen G., Sui L., Hoa V.N., Tamtin M., Nyonje B., Rocha R.M., Sorgeloos P., Gajardo G. (2020) Review on integrated production of the brine shrimp Artemia in solar salt ponds. Reviews in Aquaculture, 12(2): 1054-1071

Vega J., Alvarez-Gomez F., Guenaga L., Figueroa F.L., Gomez-Pinchetti J.L. (2020) Antioxidant activity of extracts from marine macroalgae, wild-collected and cultivated, in an integrated multitrophic aquaculture system. Aquaculture, 522: 735088

Volatiana J.A., Sagada G., Xu B., Zhang J., Ng W.-K., Shao Q. (2020) Effects of butyrate glycerides supplementation in high soybean meal diet on growth performance, intestinal morphology and antioxidative status of juvenile black sea bream, Acanthopagrus schlegelii. Aquaculture Nutrition, 26(1): $15-25$

Vrabec V., Kulma M., Cocan D. (2015) Insects as an alternative protein source for animal feeding: A short review about chemical composition. Bulletin UASVM Animal Science and Biotechnologies, 72(2): $116-126$

Wang C., Chuprom J., Wang Y., Fu L. (2020) Beneficial bacteria for aquaculture: nutrition, bacteriostasis and immunoregulation. Journal of Applied Microbiology, 128(1): 28-40

Wang H., Seekamp I., Malzahn A., Hegemann A., Carvajal A.K., Slizyte R., Standal I.B., Handa A., Reitan K.I. (2019a) Growth and nutritional composition of the polychaete Hediste diversicolor (OF Müller, 1776) cultivated on waste from land-based salmon smolt aquaculture. Aquaculture, 502: 232-241 
Wang K.-Z., Feng L., Jiang W.-D., Wu P., Liu Y., Jiang J., Kuang S.-Y., Tang L., Zhang Y.-A., Zhou X.-Q. (2019b) Dietary gossypol reduced intestinal immunity and aggravated inflammation in ongrowing grass carp (Ctenopharyngodon idella). Fish \& Shellfish Immunology, 86: 814-831

Xie S.-W., Liu Y.-J., Liu Y.-J., Zeng S., Niu J., Tian L.-X. (2016) Partial replacement of fish-meal by soy protein concentrate and soybean meal based protein blend for juvenile Pacific white shrimp, Litopenaeus vannamei. Aquaculture, 464: 296-302

Yamamoto T., Iwashita Y., Matsunari H., Sugita T., Furuita H., Akimoto A., Okamatsu K., Suzuki N. (2010) Influence of fermentation conditions for soybean meal in a non-fish meal diet on the growth performance and physiological condition of rainbow trout Oncorhynchus mykiss. Aquaculture, 309(1-4): 173-180

Zhou Z., Yao W., Ye B., Wu X., Li X., Dong Y. (2020) Effects of replacing fishmeal protein with poultry by-product meal protein and soybean meal protein on growth, feed intake, feed utilization, gut and liver histology of hybrid grouper (Epinephelus fuscoguttatus $q \times$ Epinephelus lanceolatus $\widehat{\gamma}$ ) juveniles. Aquaculture, 516: 734503 